\title{
Effect of Bio-Additives and Kinetic Studies of Saccharomyces Cerevisiae on High Purity Alcohol Production Suitable for Medicinal Use
}

Chandran Masi ( $\sim$ biochandran1976@gmail.com )

Addis Ababa Science and Technology University https://orcid.org/0000-0002-6870-4798 Jenila Rani D

Saveetha University Saveetha Engineering College

Partha Sarathy $\mathbf{N}$

Rajalakshmi Engineering College

Johanna Rajkumar

Rajalakshmi Engineering College

\section{Research}

Keywords: Additives, bioethanol, Avena sativa (Oats), Cicerarietinum (Bengal gram), Liquorozymol, Molasses

Posted Date: September 30th, 2021

DOl: https://doi.org/10.21203/rs.3.rs-934243/v1

License: (9) This work is licensed under a Creative Commons Attribution 4.0 International License. Read Full License 


\section{Abstract}

Alcohol is an indispensable ingredient in medicinal preparations like cough syrup, antiseptic, antidote, disinfectant, etc. In the present study, the alcohol production using Saccharomyces cerevisiae (yeast) and its growth kinetics were investigated in presence of the following bio-additives: Liquozyromol (plant extract), Avena sativa (oats), and Cicer arietinum (Bengal gram). The yeast's specific growth rate and generation time for fermentation during alcohol production were determined to be $1.35 \mathrm{~h}^{-1}$ and $1.57 \mathrm{~h}^{-1}$ respectively. The Optimal concentration of Avena sativa (oats), Cicer arietinum (Bengal gram), and Liquozyromol for alcohol production were determined to be $8.6 \mathrm{~g} / \mathrm{l}, 8.9 \mathrm{~g} / \mathrm{l}$, and $9.8 \mathrm{~g} / \mathrm{l}$ respectively. Under the optimal conditions, the introduction of Cicer arietinum (Bengal gram) and Avena sativa (oats) had a minuscule impact on the alcohol quantity produced, while it increased considerably in presence of Liquozyromol. Also, the rate of fermentation decreased and volatile acidity was affected in presence of additives. Thus, the use of Liquozyromol as an additive greatly reduces the effect of secondary metabolites thereby increasing the quantity and the quantity of ethanol produced.

\section{Introduction}

The pursuit for sustainable energy production to fulfill global energy demands has been the focus of major key players in the industrial landscape. This surge in energy demand is prompted by the rise in living standards [1]. The study of liquid biofuels was prioritized over other renewable energy resources since they account for $40 \%$ of global energy use [2]. One such alternate fuel that is eco-friendly is bioethanol. It can be distributed through the current fueling infrastructure and is easily compatible with modern combustion engines when mixed with gasoline [3].

Bioethanol production from molasses using Saccharomyces cerevisiae MTC181 under varied fermentation conditions has an impact on the quality and quantity of ethanol produced. As a result, bioethanol production under various fermentation conditions is being examined in this study to generate in-depth knowledge on this topic. The goal of this research is to 1) determine the ethanol concentration during bioethanol production using sugarcane molasses as the media with different bio-additives such as Avena sativa (oats), Cicer arietinum (Bengal gram), and liqozyromol, 2) Evaluate the effect of kinetic parameters on alcohol production. 3) To improve the alcohol's quality by reducing the impurities such as aldehydes and ketones to fewer than $1 \mathrm{ppm} / \mathrm{gm}$.

\section{Results And Discussion}

The efficiency of ethanol production is increased and the need for the distillation process is decreased to some extent due to an increase in the purity of the production. During the fermentation process, the following parameters were measured: the number of viable cells, amount of ethanol produced, residual sugar content, and dry matter production. The production of by-products such as methanol, acetic acid, and higher alcohols (1-propanol, 1-butanol, 2-butanol) as well as aldehyde appearance time was measured and the findings are depicted in the graph [14]. 
The yeast grew and proliferated well under fermented conditions, with a CFU of $3.24 \times 10^{6} \mathrm{CFU} / \mathrm{mL}$. After 36 hours of incubation, the number of yeast cells increased. Saccharomyces cerevisiae produces metabolites like the alcohol dehydrogenase enzyme, which converts carbohydrates to ethanol. Sugar in yeast media which aids in the growth and proliferation of yeast cells during fermentation also gets acted upon by the alcohol dehydrogenase enzyme to produce ethanol. Glycolysis converts glucose in the substrate to pyruvic acid. The pyruvic acid is subsequently transformed into acetaldehyde and $\mathrm{CO}_{2}$, and the acetaldehyde is then turned into ethanol by an enzyme called alcohol dehydrogenase [13]. The simultaneous saccharification and fermentation of converted lignocellulosic content resulted in a higher fermentation yield, and a comparison of the potential of Saccharomyces cerevisiae and Kluyveromyces marxinus in ethanol production revealed a significant increase in the latter species with 65 percent activity [12].

The final biomass and ethanol production were measured at various time intervals with varying sugar levels. The residual sugar increased until the 32 nd hour of fermentation, after which it drastically declined until the 72-hour mark. The reduction in residual sugar and biomass generation are important indicators of ethanol output.

The use of chemicals throughout the fermentation process has greatly boosted the amount of ethanol produced. After adding liquozyromol as an additive, the highest amount of ethanol production $(12.4 \%)$ was observed (Figure 1a). Industrial ethanol production from several starchy components such as corn, wheat, potato, and cassava root has been documented and has been actively adopted for large quantity ethanol production $[10,11]$. The synthesis of higher alcohols, such as 1-propanol, 1-butanol, and 2butanol, were measured using gas chromatography. Cell growth was found to be hindered by increasing ethanol synthesis due to the osmotic pressure exerted on the yeast cells by the generated alcohol (Figure $1 \mathrm{~b}$, and 1c)..

The kinetic parameters were calculated and the maximum specific growth rate was found to be higher in all three additives when compared with control. Throughout fermentation, yeast produced alcohol along with some by-products. [14] Stated that during alcoholic fermentation, Saccharomyces cerevisiae was producing by-products such as organic acids and acetaldehyde which can decrease alcohol production (Figure 1d). The accumulated alcohol interacted with organic acids to form ester compounds thus resulting in reduced alcohol production. Aldehyde appropriate for therapeutic application was found in the alcohol quality after Liqurozymol was added.

\section{Conclusion:}

When chemically synthesized, a decent amount of ethanol was produced from biomass with higher efficiency, resulting in a clean biofuel. The increase in biomass-generated fuel is aided by the addition of substrates and additives, resulting in increased yield co-efficiency and the generation of reliable convertible biomass for further processing. This research was conducted to improve ethanol production 
by using additives and the results indicate that the employed approach was superior when compared to conventional ethanol production techniques.

\section{Materials And Methods}

\subsection{Microorganism and culture media}

IMTECH in Chandigarh provided the Saccharomyces cerevisiae MTC181 strain. Sucrose (10.0), Yeast extract (3.0), $\left(\mathrm{NH}_{4}\right)_{2} \mathrm{SO}_{4}(2.0)$, and $\mathrm{MgSO}_{4}(0.5)$ were used to cultivate the chosen strain $(\mathrm{g} / \mathrm{L})$. For the inoculum preparation and molasses fermentation, good grade molasses with $78 \mathrm{Bx}, 50$ percent $(\mathrm{w} / \mathrm{v})$ total reducing sugars (TRS), nitrogen, and phosphorus were used.

\subsection{Molasses pre-treatment}

Diluted molasses was settled in tanks with conical bottoms for the removal of sludge, ash contents, and other particulates during molasses preparation. The $\mathrm{pH}$ was adjusted to $4.0-4.5$ by adding sodium hexametaphosphate and commercial sulfuric acid, which transformed the available $\mathrm{Ca}^{2+}$ into calcium sulfate [5]. The substrate's Brix was set at 32,36 , and 40 , and the sugar content in pre-treatment molasses was maintained at 20 percent, 22 percent, and 24 percent (w/v), respectively.

\subsection{Inoculum preparation}

Initially, yeast was propagated in a $1 \mathrm{~m}^{3}$ jar till the cell count reached $3.24 \times 10^{6} \mathrm{CFU} / \mathrm{mL}$, after which it was switched to a growth medium to maintain the proper cell count. This inoculum was employed for molasses fermentation.

\subsection{Effect of additives}

To study the effect of additives on the rate of alcohol production, three additives Avena sativa (Oats), Cicer arietinum (Bengal gram), and Liquozyromol (an herbal product of plant extract containing enzymes and polymers) were chosen. To finalize a suitable additive from our shortlisted candidates and to determine its optimal concentration, a screening study was carried out with various concentrations (1-5\%) of each additive for four days.

\subsection{Fermentation}

Batch scale experiments were performed in the conical flask. The temperature was maintained at $32 \pm$ $1^{\circ} \mathrm{C}$ and the medium was stirred at $300 \mathrm{rpm}$. To control the foaming, a silica-based antifoaming agent was used. The fermenter was filled with appropriately diluted molasses $16 \mathrm{hrs}$ after the transfer of inoculum (25\%). After transferring the inoculum, the substrate was supplied continuously with supplements and incubated. Samples of the fermented broth were withdrawn at various time intervals for determining ethanol content. The fermentation efficiency was calculated based on total fermentable sugars left in the fermentation medium.

\subsection{Analytical methods}


The total soluble solids and yeast cell counts in the fermentation broth were determined using the direct counting method [6]. The dinitro salicylic acid technique was used to determine the reducing sugar left behind. This aids in estimating the amount of substrate consumed during fermentation [7]. The concentration of ethanol $(P, g / L)$ was determined using the Chamber Conway method, with alcohol 96 percent serving as an internal standard [8]. The ethanol yield $(\mathrm{Yp} / \mathrm{s})$ was determined as $(\mathrm{g})$ of ethanol per (g) of substrate used $(\mathrm{g} / \mathrm{g})$ by dividing the ethanol concentration generated $(P, g / L)$ by the substrates consumed $(S, g / L)$. By dividing the ethanol concentration generated $(P, g / L)$ by the fermentation period, the ethanol productivity (Qp, g/L/h) was computed. The fermentation efficiency (n) was calculated by dividing the amount of produced ethanol by the theoretical amount of ethanol calculated and multiplying by $100 \%$.

\section{Declarations}

\section{Acknowledgment:}

The authors are grateful to Saveetha University (India), Rajalakshmi Engineering College (India), and Addis Ababa Science \& Technology University (Ethiopia) for providing all of the essential resources for this work.

Funding: No funding was received for conducting this study.

Conflicts of interest: The authors declare that they have no conflict of interest for this study.

Availability of data: Nil

Ethics approval: Not Applicable

\section{Authors Contributions:}

The study's conception and design were aided by all of the contributors. Jenila Rani D, Johanna Rajkumar, and Parthasarathy $\mathrm{N}$ worked in India on material planning, data collection, and analysis. Jenila Rani $D$ and Chandran Masi wrote the first draft of the manuscript, and all writers provided feedback on previous drafts. The final manuscript was read and accepted by all contributors.

Consent to Participate: For this report, the authors announce that they have no conflicts of interest.

Consent for Publication: All of the writers gave their permission for their work to be published.

\section{Author Information:}

\section{Affiliations:}

Department of Biotechnology, Saveetha University, Chennai, India. 
Jenila Rani D

Department of Biotechnology, Rajalakshmi Engineering College, Chennai, India.

Johanna Rajkumar and Parthasarathy $\mathrm{N}$

Department of Biotechnology, College of Biological and Chemical Engineering, Addis Ababa Science \& Technology University, Addis Ababa, Ethiopia.

Chandran Masi

\section{Corresponding author}

Correspondence to Chandran Masi

\section{Compliance with Ethical Standard:}

- There are no potential conflicts of interest in this research.

- This Research does not involve Human Participants and Animals.

- Informed consent

\section{Article Highlights:}

- Bioethanol generation from molasses using Saccharomyces cerevisiae MTC181 is compared in this study.

- This comparative study used sugarcane molasses as the media and several additives including Avena sativa (oats), Cicer arietinum (Bengal gram), and liqozyromol to estimate the ethanol concentration during bioethanol alcohol production.

- To determine the impact of kinetic parameters on the generation of alcohol.

- To improve the quality of the alcohol. The alcohol produced will contain impurities such as aldehydes, ketones, and water.

\section{References}

1. Demirbas. Use of algae as biofuel sources. Energy Convers Manag. 2010;51:2738-49.

2. Tan KT, Lee KT, Mohamed AR. Role of energy policy in renewable energy accomplishment: the case of second-generation bioethanol. Energy Policy. 2008;36:3360-5.

3. Hansen AC, Zhang Q, Peter WL, Lyne. Ethanol diesel fuel blends - a review. Bioresource Technol. 2005;96:277-85.

4. Atiyeh $\mathrm{H}$, Duvnjak Z. Production of Fructose and Ethanol from Sugar Beet Molasses using Saccharomyces cerevisiae ATCC 36858. Biotechnol Prog. 2002;18:234-7. 
5. Converti A, Arni S, Sato S, de Carvalho JCM, Aquarone E. Simplified modeling of fed-batch alcoholic fermentation of sugarcane blackstrap molasses. Biotechnol Bioeng. 2003;84:88-95.23.

6. Ristiati NP Pengantar Mikrobiologi Umum. Direktorat Jenderal Pendidikan Tinggi Departemen Pendidikan Nasional, Jakarta. (2000).

7. Miller GL. .Use of Dinitrosalycilic Acid Reagent for Determination of Reducing Sugar. Anal Chem. 1959;31:426-8.

8. Kartika B, Guritno AD, Purwadi D, and Ismoyowati. 1992. Petunjuk Evaluasi Produk Industri Hasil Pertanian. PAU PangandanGiziUniversitasGadjahMada, Yogyakarta.

9. Kadam KL, McMillan JD. Availability of corn stover as a sustainable feedstock for bioethanol production. BioresourTechnol. 2003;18:17-25.

10. Sasson A. (1990) Feeding tomorrow's world. UNESCO, Paris, pp 500-510.5339. 1st Mae FahLuang University International Conference 2012.

11. Wilke CR, Yang RD, Scamanna AF, Freitas RP. Raw material evaluation and process development studies for conversion of biomass to sugars and ethanol. BiotechnolBioeng. 1981;23:163-83.

12. Daniela A, Costa, Carlos JA, de Souza PS, Costa, Marina QRB, Rodrigues, Ancély F, dos Santos MR, Lopes HLA, Genier WB. Silveira and Luciano G. Fietto. Physiological characterization of thermotolerant yeast for cellulosic ethanol production.ApplMicrobiolBiotechnol (2014) 98:38293840 .

13. Buglasss AJ. Handbook of Alcoholic Beverages: Technical, Analytical and Nutritional Aspects. John Wiley\&Sons, United States; 2011.

14. Mukhtar K, Asgher M, Afghan S, Hussain K, Zia-ul-Hussain S. 2010. Comparative Study on Two Commercial Strains of Saccharomyces cerevisiaefor Optimum Ethanol Production on Industrial Scale. Journal of Biomedicine and Biotechnology 2010, 1-5.

\section{Tables}

\section{Table 1. Fermentation Kinetic Parameters after addition of additives}


Fermentation Kinetic Parameters after addition of additives

\begin{tabular}{|lllll|}
\hline Additives & Oats & $\begin{array}{l}\text { Bengal } \\
\text { gram }\end{array}$ & $\begin{array}{l}\text { Liquorozymol } \\
\text { patented) }\end{array}$ & (a herbal product to be \\
\hline Fermentation time (h) & $\begin{array}{l}48- \\
72\end{array}$ & $48-72$ & $48-72$ \\
\hline $\begin{array}{l}\text { Residual sugars }(\mathrm{g} / \mathrm{L}) \\
\text { max }\end{array}$ & 42.1 & 41.6 & 44.4 \\
\hline $\begin{array}{l}\text { Residual sugars (g/L) } \\
\text { min }\end{array}$ & 14.5 & 13.8 & 17.4 \\
\hline$\mu \max (\mathrm{h}-1)$ & 1.24 & 1.16 & 1.35 \\
\hline$\mu \min (\mathrm{h}-1)$ & 1.12 & 1.04 & 1.18 \\
\hline$X \max (\mathrm{g} / \mathrm{L})$ & 23.2 & 22.5 & 24.8 \\
\hline$X \min (\mathrm{g} / \mathrm{L})$ & 17.4 & 19.6 & 20.1 \\
\hline Ethanol max (g/L) & 8.6 & 8.9 & 9.8 \\
\hline Ethanol min (g/L) & 7.4 & 7.8 & 8.1 \\
\hline
\end{tabular}

Figures 

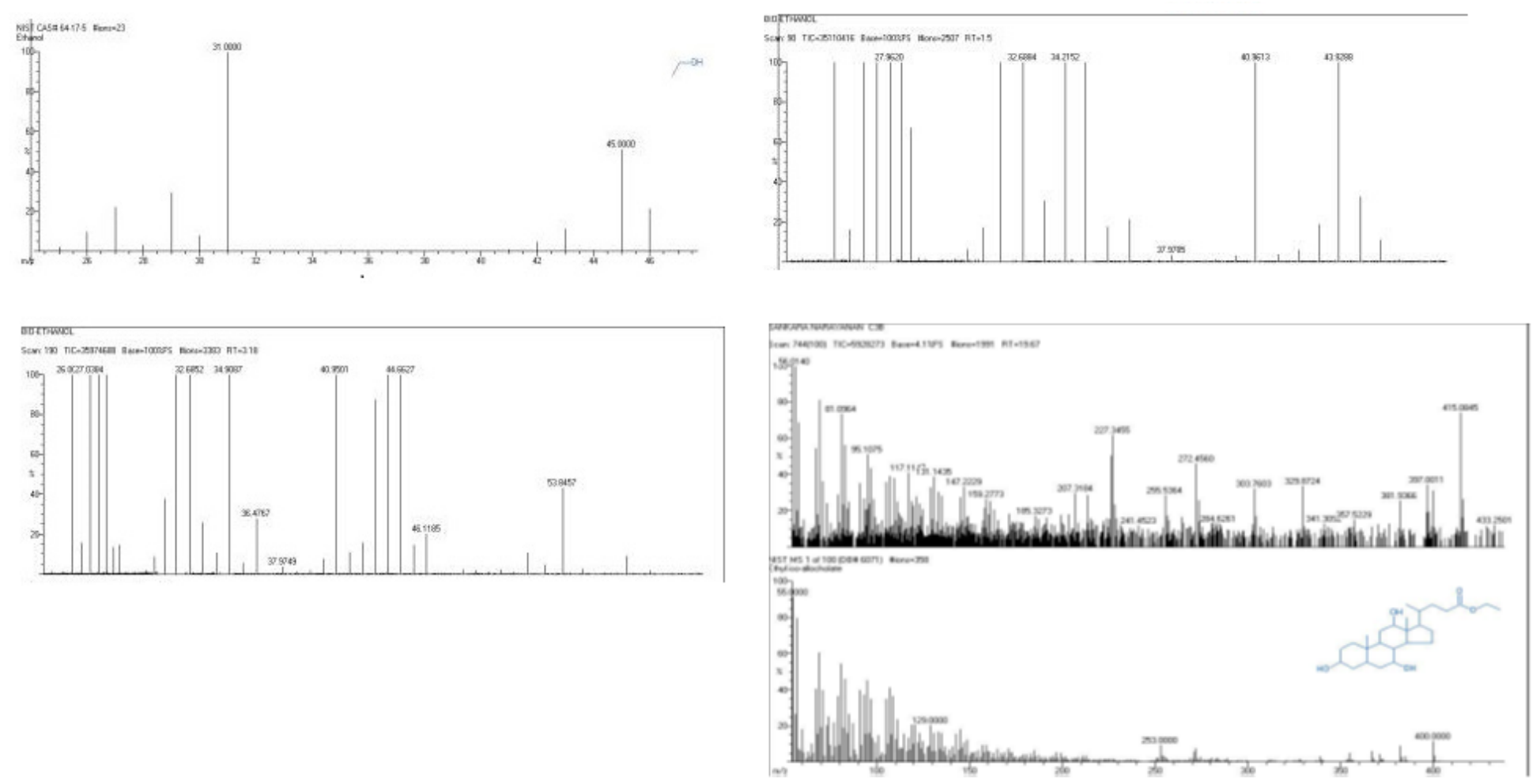

\section{Figure 1}

a. GS MS data for the ethanol standard b. GS MS data for ethanol after addition of additive ceicer arietinum c. GS MS data for ethanol after addition of additive Avena sativa d. Gas chromatography showing the presence of by products in the production of bioethanol

\section{Supplementary Files}

This is a list of supplementary files associated with this preprint. Click to download.

- Onlinefloatimage1.png 